\title{
LA PAGESIA CATALANA ABANS DE LA FEUDALITZACIÓ
}

\author{
GASPAR FELIU \\ Universitat de Barcelona
}

\begin{abstract}
SUMARI
1. Situació i obligacions dels conreadors.- 2. Canvis deguts a la implantació del feudalisme.
\end{abstract}

Per entendre la situació de la pagesia en qualsevol moment històric, les preguntes pertinents són de qui és la terra i quines són les condicions d'accès i sortida de la terra per part dels conreadors: el que s'acostuma a anomenar les relacions entorn a la terra ${ }^{1}$.

En els comtats precatalans anteriors al feudalisme, com en tota l'Europa carolíngia i postcarolíngia, la propietat de la terra mostra una primera divisió bàsica entre fisc i alou. La terra de fisc és la pertanyent, per qualsevol raó als poders públics; l'alou, la propietat privada. Però cal parar compte amb el terme propietat: com diu Bonnassie ${ }^{2}$, «si hi ha un terme maleït en història medieval és propietat», si bé afegeix que la noció de

\footnotetext{
'Una primera versió d'aquest treball va ser exposada al « $7^{\mathrm{Z}}$ Seminari d'Història Econòmica. Formes de dominació i control del treball pagès en el feudalisme català. Girona, 1994.

'Pierre BonNassie, La Catalogne du milieu du X $X^{\prime \prime}$ à la fin $d u X I^{\prime \prime}$ siècle, croissance et mutations d'une société. Tolosa de Llenguadoc, Association des Publications de l'Université de Toulouse-Le Mirail, vol. I, 1975 i vol. II, 1976. Traduït amb el títol Catalunya mil anys enrera (s. IX-XI). Creixement econòmic i adveniment del feudalisme a Catalunya de mitjans del segle $X$ al final del segle XI, Barcelona, vol. I, 1979 i vol. II, 1981), vol. I, pp. 205-206. Les cites són de l'original.
}

"Anuario de Estudios Medievales". 26 (1996) 
propietat era ben viva al sud dels Pirineus. I això és ben cert si no donem a propietat el sentit absolut actual, el «ius utendi et abutendi» del dret romà. En aquest cas, tot i la documentació que Bonnassie cita acte seguit, ens enganyaríem. A l'època, propietat és allò que hom té, independentment dels drets que altres puguin tenir sobre el mateix bé: es pot vendre la terra o es poden vendre els drets, de la classe que siguin, sobre la terra. I això val en sentit horitzontal (decima conjugal, drets de germans o parents per exemple) i en sentit vertical (drets senyorials o possessió dels conreadors). Per tant les afirmacions dels documents no s'han de pendre com les entendríem en un document actual.

Dins de les terres de fisc cal distingir entre les terres de fisc tradicionals i les sobrevingudes. Tot bé abandonat, i per tant tota terra sense propietari, passava a formar part del fisc, però hi havia una diferència clara entre una i altra classe de fisc: la primera disposava d'una organització dels conreus de què careixia la segona.

Quan el fisc va ser apropiat pels comtes i després retingut o cedit als nobles $^{3}$, les diferències entre el fisc i l'alou sovint només van se de nom: l'organització dels conreus i les obligacions dels conreadors eren les mateixes i podem trobar documents que ens parlen d'alous que foren fiscs o de fiscs cedits en alou. De fet això no era tot l'alou, sinó el que proposo que anomenem "alou dominical"4. Vora d'aquest existien alous privats, de menor extensió, conreats o no pels seus propietaris.

El procés de reconquesta, amb la densificació de gran part del territori ${ }^{5}$, provocà però que la major part de la terra fos obtinguda per

${ }^{3}$ Utilitzaré noble en el sentit més ampli, de persona pertanyent al grup dominant i que vivia de les rendes i els drets sobre les seves terres i els seus homes, incloent també en l'expressió els alts càrrecs $i$ les institucions eclesiàstiques.

${ }^{4}$ L'expressió «aprisió dominical» em sembla més definitòria que la d'«aprisió major» que havia proposat fa uns anys; G. FELIU MONTFORT, El condado de Barcelona en los siglos IX y $X$ : organización territorial y económico social, "Cuadernos de Historia Económica de Cataluña", VII, 1972 , p. 23.

${ }^{5} \mathrm{El}$ concepte tradicional de desertització del territori ha de ser abandonat: la permanència de noms i límits indica clarament que no hi hagué llargs abandonaments. Però sembla també excessiu considerar que la major part de la gent es va mantenir sobre la terra i que no hi va haver per tant repoblació, sinó imposició de l'autoritat comtal sobre les poblacions residents en terra de ningú. Els esforços per atreure conreadors són prou evidents en diversos documents; citarem només la donació del puig de Calaf a Guillem levita per part del bisbe Borrell de Vic: «Borrellus [...] Ausonensis episcopus [...] tibi Guilelmus levita [...] Donamus itaque tibi, terra erema [...] agricultores ibi obducas» José $\mathrm{M}^{\mathrm{a}}$ FONT RIUS, Cartas de población y franquicia de Cataluña (3 vol. Madrid-Barcelona, 1969-1983), vol. I, doc. 12, p. 23-25, de 30 d'abril del 1015. 
aprisió, o sigui per ocupació. A través de l'aprisió la terra de fisc (la terra sobrevinguda al fisc per manca de propietari conegut), un cop conreada durant trenta anys, es convertia en alou, de manera que hi hagué per aquest camí una formidable transformació de terres de fisc en terres aloeres, molt superior al que representaven les donacions reials o comtals sobre els fiscs tradicionals.

L'aprisió podia ser individual (o millor, de petits grups peoners endinsats en terra de ningú) o bé «dominical», quan un noble es reservava una àmplia zona per organitzar-ne la posada en conreu per mitjà dels seus dependents (fos quin fos l'estatus legal d'aquests) o d'altres homes que acudien al seu reclam ${ }^{6}$.

A partir de l'aprisió s'ha difós una idea de la situació de la pagesia catalana prefeudal que crec que cal discutir. L'ortodòxia imperant l'establí Bonnassie en La Catalogne, i la podem resumir així: fora del Pirineu, on podien existir grans dominis (villae) en mans de propietaris nobles, l'organització de les estructures de propietat i d'explotació a la resta del territori depengué del procés de repoblació. La repoblació va ser sobretot obra d'iniciatives privades, amb intervenció - organització posterior de comtes, senyors o monestirs. En altres casos els nobles es van reservar grans espais, sense però dur a terme cap actuació concreta de caire artigador sobre gran part del territori així obtingut. Molt sovint això representa que els aprisionadors - artigadors es trobaven al cap d'un temps amb un domini senyorial sobreimposat a les seves terres; però, en definitiva, l'alou pagès, marca del moviment colonitzador, ocuparia la major part de la Catalunya al sud dels Pirineus? ${ }^{7}$. Una versió resumida i molt clara d'aquesta hipòtesi es

\footnotetext{
${ }^{6}$ «Et si quispiam eorum in partem quam ille ad habitandum sibi excoluit alios homines de aliis generationibus venientes adtraxerit et secum in portione sua, quam aprisiones vocant, habitare fecerit, utatur illorum servitio» (FONT RIUS, Cartas, vol. I, doc. 2, p. 4-6); «Guilelmus pervaserat illi maximam partem terrarum infra suos legales terminos positarum, quos ibi legaliter ordine designaverat ampliando et colonis adibitis ad culturam perducendo spacia terrarum circa Gessonam» Domènec SANGÉS, Recull de documents del segle XI referents a Guissona i la seva plana, «Urgellia», 3 (1980), ap. 2, p. 227-230, de 2 de novembre del 1024; «et donat ei casales ad habitandum pagensibus quos praedictus Amelius ad laborandam ipsam terram venire ibi fecerit, et hoc sub tali conventu ut de quantum ibi laboraverint donent ipsa tasca ad Sanctam Mariam et ad coenobium Sancti Michaelis excepto ipsos casalatges et excepto nostro dominico quod ibi retinemus ad proprium; et faciant nobis ipsos iornales sicut alii nostri homines», Eduard JUNYENT I SUBIRÀ, Diplomatari $i$ escrits literaris de l'abat $i$ bisbe Oliba, Barcelona: Institut d'Estudis Catalans (Memòries de la Secció Històrico-Arqueològica, XLIV), doc. 116, p. 195-197, de 19 de juny del 1035.

${ }^{7}$ Bonnassie, La Catalogne, I, p. 105.
} 
pot trobar en la ponència de Bonnassie (1985) al col-loqui sobre feudalisme de Girona i a la seva recensió al llibre de Freedman; i és també el fil director de diversos treballs de Salrach ${ }^{8}$. Freedman resumeix molt bé l'opinió generalitzada:

\begin{abstract}
Avui les autoritats en la matèria estan d'acord que hi hagué un buit, un 'moment privilegié' en el qual l'esclavitud rural basada en el model antic estava desapareixent, mentre que la servitud i el domini del camp per part de l'elit militar encara no s'havia produït. A Catalunya l'interval de llibertat fou més llarg que a la major part d'Europa'.
\end{abstract}

Enfront d'aquesta visió optimista i rupturista, crec que es pot defensar una altra hipòtesi més continuïsta, els trets diferencials de la qual serien: la importància secundària, i en moltes zones la inexistència, de l'alou pagès entès com a terra de lliure i plena pertinença del seu conreador; el predomini, en nombre d'ocupants i en extensió conreada, de l'alou dominical (de propietat tradicional o bé obtingut per aprisió) i de la terra de fisc. Tant en l'alou com en el fisc hi havia terres explotades directament (dominicum, per emprar només la paraula més general) conreades per esclaus, segurament escassos i en regressió, o per manents o serfs fiscals; i terres cedides a conreadors personalment lliures, que adquirien drets sobre la terra, però no l'alou sobre la mateixa, i que estaven subjectes a una sèrie de prestacions i restriccions que ens són conegudes per les exempcions que de vegades obtenen i que examinarem més endavant. Trobem finalment precaristes, amb cessions en principi temporals i relacions d'explotació segurament molt diverses: de vegades es tracta només del pagament d'un parell de gallines 0

\footnotetext{
${ }^{8}$ Pierre BONNASSIE Sur la formation du féodalisme catalan et sa première expansion (jusqu'à 1150 environ), en: Jaume PORTELLA I COMAS ,(ed.), La formació i expansió del feudalisme català. «Estudi General», núm. 5-6 (1985-1986), pp. 7-21. Pierre BONNASSIE, recensió del llibre de Paul Freedman, The Origins of Peasant Servitude in Medieval Catalonia, Cambridge: Cambridge University Press, 1991, en: "Annales. Economies. Sociétés. Civilisations.», 49, 1 (1994). Josep M MaLRACH I MARÉS, Esclavitud, llibertat, servitud. L'evolució del camp català, "L'Avenç", 93 (1986), p. 36-45; Id., El procés de feudalització. Segles III-XII. Vol. II de Pierre VILAR, (dir.), Història de Catalunya. Barcelona: ed. 62, 1987; Id. La conquesta de l'espai agrari: una reflexió entorn a la cronologia, les causes, les forces $i$ les conseqüències del moviment colonitzador, en: Xavier BARRAL I ALTET (dir.), Catalunya i França meridional a l'entorn de l'any mil. Contribucions al col.loqui internacional Hugues Capet, 987-1987. Barcelona, 2-5 de juliol de 1987. Barcelona: Generalitat de Catalunya, Departament de Cultura, (1991), p. 203-211.

${ }^{9}$ Paul H. Freedman, Els orígens de la servitud pagesa a la Catalunya medieval, Vic, Eumo, 1993, p. 85.
} 
d'unes lliures de cera, però generalment inclou la tasca, que, com diu Stouff, era la prestació indicativa de la sotsmissió a la propietat eminent ${ }^{10}$, acompanyada o no d'altres prestacions sota el nom de parata o bé oblias, i que en alguns casos, com en la cessió per dues vides del «solar de Baldomar», al Penedès, comporta una feixuga sèrie d'obligacions de tot tipus ${ }^{11}$.

En gran part Cuadrada ha traçat aquest esquema en el seu estudi sobre el Maresme ${ }^{12}$. Aquesta hipòtesi implica, d'una banda, reduir la importància de l'aprisió de peoner artigador, de l'aprisió particular, en favor de l'aprisió dominical; i d'una altra distingir, fins on sigui possible, entre la propietat i el conreu de la terra. Implica també una major continuïtat, un predomini de l'herència de la baixa romanitat per damunt de tots els trastorns polítics: aquests haurien afectat més a la classe dominant que a la classe subordinada, que, no cal oblidar-ho, era la immensa majoria de la població. Significa per tant un retorn, al menys parcial, a les teories, llarg temps abandonades, que consideraven les prestacions senyorials que abocaren als mals usos com una herència de l'antiguitat: no hi hauria tant nova introducció com generalització i sobretot constància documental.

En definitiva, no hi hauria hagut un primer moment de llibertat erosionat posteriorment per la potència feudal, sinó una transformació gradual, que hauria fet disminuir el nombre de propietaris aloers i provocat una forta concentració de la propietat de la terra al mateix temps que possibilitava el sorgiment d'una pagesia propietària útil, si bé en part sotmesa a prestacions noves i sobretot exigides amb més duresa, i en part subjecta (però de nou?) al jou de l'afocament i més tard de la remença.

Tot plegat és evidentment una qüestió de proporcions, que a més no tenen perquè haver estat les mateixes en tot el territori: es pot discutir si sempre hi va haver afocats; no que el seu nombre va créixer sota la pressió dels senyors feudals. Cal dir naturalment, abans de tirar endavant, que les

\footnotetext{
${ }^{10} \mathrm{~L}$. STOUFF, Redevance à part de fruits et métayage dans la Provence médievale: tasques et facherie, «Centre Cultural de l'Abbayé de Flaran. Septièmes Journées Internationales d'Histoire, 20-22 septembre 1985. Les revenus de la terre, complant, champart, métayage en Europe occidentale (IX ${ }^{\mathrm{e}}$-XVIII ${ }^{\mathrm{e}}$ siècles)». Auch, 1987.

"Àngel FÁBrega, Diplomatari de la Catedral de Barcelona. Documents dels anys 844-1260. Vol. I. Documents dels anys 844-1000. Barcelona, Arxiu Capitular de la Catedral de Barcelona (Publicacions. Sèrie IV. Fonts Documentals, 1), 1995, XV +706 pp.; doc. 319, p. 552-553, de 4 de desembre del 997.

${ }^{12}$ C. CuAdRada I Majó, El Maresme medieval: les jurisdiccions baronals de Mataró, Sant Vicenç/Vilassar (hàbitat, economia i societat, segles X-XIV). Mataró, Caixa d'Estalvis Laietana, 1988.
} 
discrepàncies són de matís, i que les meves propostes heterodoxes no tenen res a veure amb l'alta estima científica que em mereixen tots i cadascun dels mestres i companys citats.

$\mathrm{Al}$ meu entendre la visió "ortodoxa» parteix d'una doble confusió:

1) considerar la propietat pagesa com a alou pel fet de què el propietari en disposi (en venda, donació, herència...) quan moltes vegades els documents no parlen pas d'alou, sinó de terra, vinya, camp ..., que podien estar sota alou o domini d'un tercer: «vinditores sumus [...] modiata una de vinea $[\ldots]$ in aulode de Sancti Cucufatii» ${ }^{13}$;

2) encara més greu, s'ha tendit a confondre propietari aloer amb conreador, sense pensar que els documents es refereixen a la propietat, i no diuen res de l'explotació, ni de les relacions entre propietari i conreador.

No nego que existissin pagesos conreadors propietaris, però sí que aquesta fos la situació de la majoria dels pagesos i, encara amb més èmfasi, que disposessin de la major part de la terra, fins i tot de la terra alodial. Les propietats de les institucions eclesiàstiques són omnipresents, els testaments dels magnats mostren múltiples possessions i en llocs molt allunyats, les actes de compra-venda i els límits de les possessions repeteixen molt sovint els mateixos noms, prefigurant una àmplia capa de propietaris rendistes. Encara més, sovint propietats o límits ens parlen de persones que per la seva categoria (preveres, jutges...) és impensable que s'ajupissin sobre la terra. Per tant, no sembla que la propietat alodial deixés gaire marge a la propietat dels pagesos conreadors ${ }^{14}$.

Com es va produir aquesta confusió entre l'alou i la propietat pagesa? Per respondre la qüestió començaré afirmant que els documents ens enganyen. Millor dit, que fàcilment ens enganyem en llegir els documents. Les raons són principalment dues; en primer lloc, els documents parlen dels canvis, no diuen res de les permanències, de manera que tot allò que no canvia, documentalment no existeix: al pla de Barcelona per exemple, hi ha

\footnotetext{
${ }^{13}$ José Rius, (ed.), Cartulario de "Sant Cugat» del Vallés. Barcelona: CSIC. (3 vol., 1945, 1946 i 1947); vol. I, doc. 118, de 23 de desembre de 976.

${ }^{14} \mathrm{Cal}$ tenir present que fins $\mathrm{i}$ tot la propietat alodial no estava lliure de càrregues, com es pot veure per un document del comte Oliba d'entre els anys 982 i 984 per al monestir de Serrateix: els esposos Ató i Riquilda havien fet donació a Serrateix de l'alou de Pujol de Planès. Per a que el monestir el pogués tenir lliure i franc, el comte renunciava al servei i al cens a què tenia dret sobre dit alou i manava als seus vicaris i batlles que no hi exigissin més que delmes, primícies i oblacions; Ramon ORDEIG I MATA, Dades referents al comte Oliba Cabreta. En: «Miscel.lània Ramon d'Abadal. Estudis d'història oferts a Ramon d'Abadal i de Vinyals en el centenari del seu naixement», Barcelona, Curial, 1994, p. 35.
} 
àmplies zones que no donen lloc a cap document; només molt indirectament, per algunes afrontacions, sabem que hi havia grans alous del comte, del bisbe o d'algun magnat. En segon lloc, el pergamí era car i l'escriptura lenta; els documents de l'època només deien allò que feia falta: quan hom feia una venda o una donació, tothom tenia clar que l'objecte de la transferència era allò que tenia tal i com ho tenia. Els altres drets o obligacions que comportava el bé en qüestió es donaven per sobreentesos en la clàusula habitual «cum exitibus et regressibus suis»; només de tant en tant els documents afegeixen alguna precisió que permet entreveure la verdadera naturalesa del contracte: així el 976 el comte Borrell venia a la comtessa Letgarda

alodem nostrum [...] qui nobis advenit per fiscum [...] sic vindimus nos vobis hec omnia suprascripta ipsum nostrum fiscum atque tributum ad vestrum proprium francum;

i el 990 el comte Ramon Borrell venia a Sunifred «alaudem, censum vel functionem qui exinde exiebat vel exire debebat» ${ }^{15}$.

Segona observació imprescindible per a atançar-nos a la situació de la pagesia altmedieval (i de fet per a qualsevol investigació històrica): cal llegir els documents del dret i del revés, tenir en compte allò que afirmen i allò que callen o que afirmen a la inversa. Naturalment que això és prou sabut, però no sempre és prou practicat; cal per tant recordar que quan hi ha una exempció vol dir que es tracta d'una excepció, que la resta continua subjecta a la prestació eximida.

Els punts bàsics de discusió són, al meu entendre, respecte a la propietat l'alou, l'aprisió i les franqueses; i respecte a la situació dels conreadors, la seva condició legal i les prestacions a què estaven sotmesos.

Pel que fa a l'alou ja he indicat que s'ha tendit a considerar que hi havia alou sempre que hi havia possibilitat de venda del bé i que s'ha tendit a identificar els venedors (o donadors) d'alous amb pagesos conreadors propietaris alodials, coses ambdues que no tenen perquè ser sempre així.

La confusió principal prové però de l'aprisió: s'acostuma a considerar que l'aprisió és bàsicament obra de pagesos lliures peoners, però

\footnotetext{
${ }^{15}$ Arxiu de Montserrat, perg. de Sant Benet de Bages núm. 1072, citat per Bonnassie, La Catalogne, I, p. 213; Eduard JUNYENT I SUBIRÀ, Diplomatari de la Catedral de Vic. Segles IX$X$, Vic, Patronat d’Estudis Ausonencs, 1980, fasc. 3, núm. 552, respectivament.
} 
en realitat la comunitat d'aprisionadors lliures sembla més aviat l'excepció. Contra l'extensió de l'aprisió per particulars, per pagesos conreadors que passarien a ser aloers, s'alça d'una banda l'aprisió dominical, l'ocupació d'una extensa zona per part d'una església o d'un noble, encarregat de l'explotació, l'organització i la defensa de la zona amb els seus depenents i/o els homes que pogués atreure ${ }^{16}$; o, encara pitjor, la posterior reclamació de propietat per part d'un noble, adduint anteriors donacions imperials $o$ comtals $^{17}$.

El cas paradigmàtic de la vall de Sant Joan de les Abadesses és prou conegut: el 15 de juny del $913^{18}$ més de mil habitants de la vall es van veure obligats a reconèixer que les terres que ells havien aprisionat es trobaven dins del domini del monestir de Sant Joan de les Abadesses per aprisió dominical anterior del comte Guifré el Pelós, que «sic conlocavit nos vel alios parentes nostros ad habitandum [...] et terram ad culturam perduximus ${ }^{19}$. És cert que alguna vegada la comunitat d'aprisionadors resultava prou forta per a salvaguardar la seva independència, com veiem a Vallformosa $^{20}$ i com també ho aconseguia algun particular ${ }^{21}$; però més

\footnotetext{
${ }^{16}$ FrEEDMAN, Els orígens, p. 84, considera que l'aprisió és bàsicament una actuació individual, però més endavant parla d'«empresaris aprisionadors que obtingueren concessions de terres i que les dividiren entre els colonitzadors i agricultors».

${ }^{17}$ Vegeu el judici incoat per Sant Llorenç del Munt contra Dela, que considerava la seva terra lliure contra la pretensió del monestir que era alou d'aquest i que devia pagar «tascas et oblias et receptiones sicut ceteri homines qui ipsum alaudem tenent donant et serviunt»; el monestir alega una carta de donació del comte Borrell, però l'explicació més lògica sembla que no s'hagués preocupat de fer-la efectiva fins que el treball de peoners com Dela va donar valor al territori (Joaquim MIRET Y SANS, 1914, Los noms personals y geogràfichs de la encontrada de Terrasa, "Boletín de la Real Academia de Buenas Letras de Barcelona", XIV, 55, (1914). El procés descrit per BONNASSIE (La Catalogne, I, p. 211): iniciativa dels aprisionadors sobre les terres de frontera, seguida pel nomenament per part del comte d'un vicari amb la missió d'organitzar la defensa del territori i de construir el castell, de tal manera que «el moviment de repoblació engendra a la vegada la micropropietat pagesa i el gran domini aristocràtic», no sembla que tingui suport documental.

${ }^{18}$ Federico Udina MARTORELl, (ed.), El archivo Condal de Barcelona en los siglos IX-X. Estudio crítico de sus fondos. Barcelona, CSIC, 1951, doc. 38, p. 157-165, datat per Udina a 15 de maig.

${ }^{19}$ Sobre la datació i el significat de l'acta, G. FELIU I MONTFORT, Sant Joan de les Abadesses. Algunes precisions sobre l'acta judicial del 913 i el poblament de la vall, en «Homenatge a la Memòria del Prof. Dr. Emilio Sáez. Aplecs d'estudis dels seus deixebles i col-laboradors», Barcelona, CSIC, 1989, p. 421-434.

${ }^{20}$ Francisco MiQuel i Rosell, (ed.), Liber Feudorum Major. Cartulario que se conserva en el Archivo de la Corona de Aragón (2 vols., Barcelona, CSIC, 1945 y 1947), vol. I, doc. 320 de 16 de març de 977.
} 
sovint els nobles devien acabar imposant les concessions obtingudes o simplement la seva força $a^{22}$.

Encara hi ha un altre aspecte important, que fins ara ha estat passat per alt: quan els diplomes carolingis fan referència als "gots i hispans» no pensen en tota la població, sinó monés en els «homes amb dignitat», en oposició als pagesos, als quals posteriorment els Usatges no reconeixerien altra dignitat que la de ser cristians. De fet podríem fins i tot pensar que, segons els diplomes carolingis, aquells eren els únics amb dret a l'aprisió; i encara més, que els pagesos havien d'estar necessàriament sota el domini d'un noble, com Ourliac indica per a Bigorra ${ }^{23}$. El precepte de Carles el Calb per als barcelonins, que en part repeteix un precepte anterior del mateix Carlemany, és ben explícit en aquest sentit: es dirigeix a «gotos sive ispanos intra Barchinonam [...] quohabitantes», però és evident que no es tracta de tota la població, donat que afegeix «de se et de eorum hominibus». D'altra banda els pagesos lliures atrets a les terres d'aquesta elit goda i hispana objecte del privilegi, podien abandonar el domini del senyor, però només per a posar-se sota el d'un altre:

et si quispiam eorum [...] alios homines de aliis generationibus venientes adtraxerit et secum in portione sua quam aprisiones vocant habitare fecerit, utatur illorum servitio [...] et si aliquis ex ipsis hominibus [...]

\footnotetext{
${ }^{21}$ Com aquells esposos Quintil là i Honrada a qui Gombau Ermemir de Besora havia pres una vinya al-legant «quia fisci est et fisci debet persolvere» i que pogueren demostrar que feia més de trenta anys que no els havia estat exigit cap servei fiscal (FÄBREGA, Diplomatari, doc. 339 , p. 577-578, de 28 de febrer de l'any 1000); citat per BONNASSIE, La Catalogne, I, p. 193. $\mathrm{O}$ aquell Llorenç, a qui el comte Miró volia reduir a serf fiscal «veniens homo nomime Sesenandus mandatarius Mirone comite et dixit: audite me cum isto Laurentio qualiter servus fiscalis debet esse ex nascendo de parentes de abios suos, cum fratres vel parentes suos, et servicium fecerunt domno Suniefredo comite genitore seniore meo ad parte fiscali [...] Tunc supradicti iudices dixerunt Laurentio [...] quid ad haec respondes? [...] dixit: non debeo esse servus fiscalis nec parentes mei ex nascendo de bisabios vel bisabias ex paterno vel ex materno, quia ego et parentes mei, sicut lex Gothorum continet, per triginta vel quinquaginta annos in domo in qua nati sumus inter praesentes intestimus absque blandimento vel iugo servitutis in villa Canabellas, nullo comite vel iudice nos inquietante». Petrus de MARCA, Marca Hispanica sive limes hispanicus, París, Franciscum Muguet, 1688 (reedició anastàtica, Barcelona, ed. Base, 1973), ap. XXXIV, col. 796-797, de l'any 874.

${ }^{22}$ Bonnassie, La Catalogne, I, p. 236-242, n'aporta diversos exemples.

${ }^{23}$ Paul OURLIAC, Le pouvoir et le droit en Bigorre au XI' siècle, en: Jacques KRYNEN; Albert RIGAUDIÈRE (dirs.), Droits savants et pratiques françaises du pouvoir (XI'-XIV' siècles). Bordeus, Presses Universitaires de Bordeaux, 1992, p. 99-116.
} 
alium senioraticum elegerit, liberam habeat licentiam abeundi, verumtamen $[\ldots]$ nichil secum ferat ${ }^{24}$.

I les franqueses? D'entrada he de dir que no sabem ben bé què eren les franqueses. Bisson hi veu simplement un territori sota senyoria directa del comte; Bonnassie les interpreta com a excepció de les prestacions públiques i militars i com una garantia de la llibertat personal ${ }^{25}$. Tots dos tenen segurament raó, però no tota: a l'època que tracta Bisson no quedaven pràcticament altres franqueses que les originades en la millora de la situació dels antics esclaus o manents conreadors dels fiscs comtals, per tant «franquesa» era el fisc anterior afavorit amb l'exempció d'algunes constriccions personals o reals, que alguns documents descriuen com «censum et functionem $»^{26}$. D'altra banda, franquesa no és un terme unívoc; podia aixoplugar qualsevol classe d'enfranquiment, de cessió de drets voluntària (que no significa desinteressada) per part dels comtes o dels magnats: la superposició que sembla indicar l'existència d'unes franqueses de la ciutat i el comtat de Barcelona amb unes franqueses del Vallès o de les Corts abonaria que no es tractés d'una institució ben definida, sinó d'un mot comú amb continguts diferents.

Així hi podria haver unes franqueses d'acord amb la definició de Bonnassie, que acompanyarien generalment la immunitat, però que no afavoririen els cultivadors, sinó els domini, que passaven mitjançant el privilegi d'immunitat a gaudir dels drets i rendes de l'autoritat concedent; unes franqueses enteses com a enfranquiment dels serfs fiscals i sobretot dels lliures que volguessin venir a habitar determinades terres fiscals, i que per imitació provocarien les franqueses senyorials per a llocs determinats, clars precedents de les cartes de población ${ }^{27}$; i finalment unes franqueses enteses simplement com a enfranquiment de determinades obligacions o bé

\footnotetext{
${ }^{24}$ Font RIUS, Cartas, I, doc. 2, p. 4-7.

${ }^{25}$ Thomas N. BISSON, The crisis of the Catalonian franchises (1150-1200) en: PORTELLA, La formació, p. 154); BonNASSIE, La Catalogne, I, p. 311-316.

${ }^{26}$ Donació d'un alou al comtat d'Urgell, a La Vansa: «sic facimus tibi carta franchitatis sine nullum censum sine nulla funcione», Cebrià BARAUT, Els documents dels anys 981-1010, de l'Arxiu Capitular de la Seu d'Urgell, "Urgellia», 3 (1980), doc. 215, p. 48. Carta de franqueses per als habitants del castell de Santa Linya: "concedo vobis censum et functionem», FONT Cartas, doc. 18, p. 34-35.

${ }^{27}$ Vegeu entre altres les franqueses de Montmell i de Ribes concedides pel bisbe Vives de Barcelona el 974 i el 990 respectivament; FonT RIUS Cartas, doc. 7, p. 11-12 i doc. 10, p. 1920.
} 
imposicions, com les de la ciutat i el comtat de Barcelona. En tot cas franquesa no significava l'enfranquiment de totes les prestacions: les franqueses continuaven proporcionant algunes rendes, sinó no tindria cap sentit que fossin objecte de transmissión ${ }^{28}$.

Per tant, fiscs, franqueses, alous dominicals i aprisions dominicals semblen reduir moltíssim l'espai disponible per a l'alou de pagès conreador, que devia ser, en el millor dels casos, més aviat excepció que no pas regla; això deixant de banda que, ja fos per vendes o per donacions (sovint forçades per deutes o per pressions dels poderosos), per embargaments o mitjançant l'ús de la violència, l'alou va sofrir una clara regressió com a mínim a partir de mitjans del s. $\mathrm{X}^{29}$. No podem negar però dues coses: 1) que de la mateixa manera que hi ha propietats de poderosos que no ha deixat rastre documental perquè, en no haver estat objecte de transaccions, no en van generar, hi pot haver també alous pagesos en les mateixes condicions; i 2) que, encara que no fos en alou, una capa important de pagesos eren lliures, i podien disposar de les seves terres, per bé que tant ells com les terres estiguessin sotmesos a diferents prestacions, tant d'origen públic com d'origen dominical.

\footnotetext{
${ }^{28}$ «ita convenit ad eos ut non faciat ullum malum in illas franchedas quas predicti comes et comitissa tenent in qualicumque loco ad suum dominium aut aliquis homo tenet per eos», ACA, Cancelleria, perg. de Ramon Berenguer I, núm. 328 de 13 de juliol de 1056, en curs de publicació a: Gaspar Feliu i Josep M. SALRACH (dirs.), Els pergamins de l'arxiu dels comtes de Barcelona, de Ramon Borrell a Ramon Berenguer I, núm. 623; «abeat Geribertus predictus ipsos acaptes quod mea mesnada solet abere in ipsis franchedis» ACB, perg. Diversorum D, núm. 211 de l'any 1060. Les franqueses de les Corts foren legades a la seu pel comte Ramon Berenguer III en el seu testament, MARCA, Marca Hispanica, ap. CCCLXXXI, col. 1271-1275; sobre les franqueses de les Corts, vegeu Josep MORAN I OCERINJÁUREGUI i Montserrat BELTRAN I MORALES, Les franqueses del poble de les Corts, del segle IX fins al segle XVII, en: "Història Urbana del Pla de Barcelona. Actes del II Congrés d'Història del Pla de Barcelona celebrat a l'Institut Municipal d'Història els dies 6 i 7 de desembre de 1985", Barcelona, Institut Municipal d'Història (2 vols., 1989 i 1990), vol. I, p. 27-44.

${ }^{29} \mathrm{De}$ fet quan podem localitzar un petit propietari aloer, la major part de les vegades és en el moment en què perd les seves terres. Citarem com a exemple un sol cas, excepcional per la forma com perd les seves terres, però que en canvi ens permet de conèixer tot el conjunt de la propietat: el 18 d'abril del 990, els esposos Sindila i Maria es lliuraren com a esclaus a la Seu de Barcelona («servili more subicere ad omnia facere que iusserit nobis domnus presul»), en expiació del crim d'haver mort la seva filla. Els seus béns eren dues peces de terra $i$ dues peces de vinya, un parell de bous, porcs i tines o bótes (vascula); FÀBREGA, Diplomatari, doc. 203, p. 414-415, de 8 d'abril del 990. Com diu SALRACH, El procés de feudalització, p. 188, els grans no desaprofitaven cap ocasió d'ampliar els seus alous, fagocitant els petits a través de donacions pietoses, confiscacions judicials, deutes...
} 


\section{SITUACIÓ I OBLIGACIONS DELS CONREADORS}

Els pagesos conreadors tenien diverses categories legals ${ }^{30}$, com també les terres que conreaven, de manera que les càrregues a què estaven sotmesos eren molt diverses. Intentaré només una descripció de les situacions més generals, tant de la situació general de la pagesia com de les prestacions que corresponien a cadascun dels grups.

Les categories legals semblen clares: aloers, propietaris no aloers (els aprisionadors podien pertànyer a l'un o l'altre d'aquests grups), precaristes o tinents lliures, serfs i esclaus. Ja no és tan fàcil saber a quina categoria cal adscriure alguns dels conreadors ni tampoc les prestacions que eren exigibles a cada grup. Els documents no són gaire explícits en aquest punt i d'altra banda molt possiblement un mateix nom es pot referir a prestacions diferents segons els llocs i els moments. Per tant gairebé totes les afirmacions que es poden fer en aquest tema són més aviat hipotètiques.

D'entrada, tots els súbdits que no gaudien de privilegis d'inmunitat estaven subjectes a prestacions provinents de la potestat pública, que en els diplomes carolingis es defineixen com obligació d'acudir a l'exèrcit, d'atacar i defensar la frontera, i d'hostatjar i proporcionar bagatges als enviats de l'emperador ${ }^{31}$. Seguint Bonnassie, els drets de la potestat pública els podem agrupar en drets sobre els béns públics (camins, aigües, boscos) i els intercanvis (teloneum, pascuaticum, moneda), drets fiscals sobre les persones (functio) i sobre els béns (censum) ${ }^{32}$. Sempre segons Bonnassie la functio es refereix bàsicament al servei militar, a l'obligació de participar en les expedicions públiques, en les guàrdies i en les obres de les fortaleses. Vora la functio, el censum afegia obligacions d'ajuda a les expedicions, com hostatjar el senyor (alberga), proveir de menjar persones i animals (parata),

${ }^{30}$ «decrevimus ut cuncta loca urbana vel rustica [...] cum decimis et primitiis suis, colonis vel colonabus, servis et ancillis et aldionibus», BARAUT, Els documents (3), doc. 271, p. 100102, de l'any 1001.

${ }^{31}{ }$ Karolus [...] imperator gotos sive ispanos intra Barchinonam [...] quohabitantes [...] complacuit mansuetudini nostre sub immunitatis tuitione defensionisque munimine benigne suscipere [...] sicut ceteri franci homines cum comite suo in exercitum pergant, et in marcha nostra iuxta rationabilem eiusdem comitis ordinationem adque admonitionem explorationes et excubias, quod usatico vocabulo wactas dicunt, facere non neglegant, et missis nostris quos pro rerum oportunitate illas in partes miserimus [...] paratas faciant et ad subvectionem eorum veredos donent», FONT RiUS, Cartas, I, doc. 2, p. 5-6, capitular de Carles el Calb per als barcelonins, d'11 de juny de 844 .

${ }^{32}$ BonNaSSIE, La Catalogne, vol. I, p. 159. 
proporcionar-li animals de bagatge (parafreda) i també animals o productes animals.

Aquesta definició de cens em sembla discutible; Bonnassie es basa en les cartes de franquesa de Montmell i de Sant Pere de Ribes, on els conreadors són exemptats d'aquestes càrregues, però cal tenir em compte que censum és una paraula equívoca, que en aquest cas concret sembla usada en el sentit més general. Possiblement al menys una part d'aquestes prestacions, les que fan referència al lliurament d'animals o part d'animals, no s'hagin de relacionar amb la potestas, sinó amb la dependència domini$\mathrm{cal}^{33}$. De tota manera ja és prou simptomàtic que totes les prestacions apareguin barrejades, sigui quin sigui el seu origen.

Sovint, però, trobem exempcions d'algunes d'aquestes prestacions: d'entrada els barcelonesos estaven exempts de drets de pastura i de mercat (paschualia i thelonea), i també de qualsevol redibitio segons el diploma de Carles el $\mathrm{Calb}^{34}$, i ja hem citat exemples d'exempció de functio i de census o de redibitiones. Ara bé, que els nobles n'estiguessin exempts no vol dir que traslladessin l'exempció als seus subordinats.

Les prestacions públiques afectaven fins i tot els aloers, com també els delmes i primícies, sovint en mans dels nobles com a propietaris de les esglésies. Darrera els aloers sembla que la millor situació legal corresponia als homes lliures «atrets» a la terra d'altri, que trobem ja perfectament descrits en el repetidament citat diploma de Carles el Calb als barcelonesos de l'any 844 :

et si quispiam eorum in partes quam ille ad habitandum sibi excoluit alios homines de aliis generationibus venientes adtraxerit et secum in portione sua, quam aprisionem vocant, habitare fecisset.

\footnotetext{
${ }^{33}$ «nullum alium censum persolvant nisi solas decimas et primicias [...] non parafreda, non asinos in onera, non mansionaticos, non porchos, non bervices, non agnos nec pernas nec ullum alium censum», carta de població del castell de Montmell, de 17 d'abril del 974, FonT RiUs, Cartas, doc. 6, p. 11-12; «nullus [...] exigere vel exactare presumat, non bovem, non asinum, non agnum, non arietem, non porcum, nec capones, non paravereda nec ulla importabilia honera ausi, sola opera ad ipsum castrum facienda», carta de població del castell de Ribes, de 6 de maig de 990, Ibidem., doc. 10 p. 19-20.

${ }^{34}$ «Alius vero census, id est nec paschualia in eorum terminis vel eorum villis, nec thelonea infra comitatum in quo consistunt, nec alia quelibet redibitio neque a comite, neque a iunioribus aut ministerialibus eius, deinceps ab illis ullatenus exigatur»; document citat a la nota 31 .
} 
Pel que veiem en les posteriors cartes de població de Montmell i de Ribes, aquests obtenien drets sobre la terra, fins i tot un cert dret de disposició en determinades condicions (però no l'alou); drets que perdien si decidien canviar de senyor ${ }^{35}$.

Aquests aprisionadors subjectes a la senyoria d'un noble i amb limitacions per a disposar de les seves terres, tenen per tant una condició social que no es pot comparar amb la dels aloers, amb qui sovint s'han volgut identificar. Les càrregues a què estaven sotmesos si no disposaven de cap franquesa les trobem definides com «servicium et obsequium» (donació de l'alou d'Artès a la seu de Vic) o bé «talem servitium qualem de legitimum alodem faciunt ipsos homines comanentes in ipso comitato» (donació de Fontanet -a Piera- a un grup de quinze conreadors) ${ }^{36}$. En què consistien aquests «servicium et obsequium ${ }^{37}$ ho podem llegir en les exempcions concedides als habitants de Montmell i de Ribes: a més dels drets públics i dels delmes i primícies, lliurament d'animals o de parts d'animals, ajuda a l'obra del castell i altres «importabilia honera» i, potser, fins i tot, acabar

\footnotetext{
${ }^{35} \mathrm{Al}$ diploma de Carles el Calb, aquests «atrets», obtenien terra («in sua portione collocatus»), però si se'n volien anar havien de deixar tots els seus béns en mans del senyor («liberam habeat licentiam abeundi, verumtamen ex his que possidet nichil abeat, nichil secum ferat, set omnia in dominium et potestatem prioris senioris plenissime revertatur». A la carta de població de Sant Pere de Ribes se'ls permet vendre o permutar els seus béns mentre permaneixin al lloc, però «ipsis qui retro gradierint $[\ldots]$ licentiam abnegamus vindendi». La donació de Calaf a Guillem, levita, feta pel bisbe de Vic Borrell l'any 1015, és també molt clara pel que fa a la situació de sotsmissió dels aprisionadors: «agricultores ibi obducas [...] et facias ex his omnibus prefixis sub dominio tuo semper usuandi», FONT RIUS, Cartas, doc. 12, p. 2325.

${ }^{36}$ Per Artès, Junyent, Diplomatari de la Catedral, doc. 12, p. 10-13; per Piera, FONT Rius, Cartas, doc. 5, p. 9-10.

${ }^{37}$ Servicium és el terme més complexe, ja que és el més general: tant pot equivaldre al conjunt de prestacions degudes (al comte, o al senyor, o al propietari), com indicar una prestació concreta sobre una terra concreta; en aquest darrer cas trobem exemples de servicium molt diferents: des d'un moltó a diverses quantitats de diners: «donent servicium ipsa tascha cum gallina una et fogacia una», JUNYENT, Diplomatari de la Catedral, fasc. 3, núm. 615, p. 525 , de 28 de març del 977; "sic vindimus vobis ipsa terra cum ipso servicio multono I», ACA, Cancelleria, perg. de Ramon Borrell, carp. 5, núm. 57, de l'any 1001, Feliu-SalRaCH, L'arxiu, doc. 58; "non donent amplius ipsi homines nisi ipsa tascha et ipsas pernas qui inde exire debent per vocem rectam", Antoni M. UdinA ABELló, La Successió testada a la Catalunya Altmedieval. Barcelona, Fundació Noguera, 1984, ap. I, núm. 81, p. 236-238, de 21 d'agost del 1010. A Ullà, nou «mansi spani» pagaven cadascun de cens anyal: un moltó, un pernil, una migera de vi, una migera d'ordi, dues fogaces, una quarta rasa de forment $\mathrm{i}$ un porc, Ramon MARTí, La integració a l'"alou feudal» de la seu de Girona de les terres beneficiades pel règim dels "hispans». Els casos de Bàscara $i$ Ullà, segles IX $i$ XI, en: PORTELLA, La formació, p. 58.
} 
essent considerats com a serfs, donat que es concedeix als habitants de Montmell que hi podran residir «sine ullo iugo servitutis» ${ }^{38}$.

Els pagesos lliures conreadors de terres d'altri, els «precaristes», tenien una situació econòmica menys avantatjosa pel fet que la terra no els pertanyia; en canvi la seva situació legal era comparable a la dels aprisionadors sobre terres dominicals. La precària, d'origen romà, és en essència la concessió temporal d'un bé per a ser explotat a canvi de diverses contraprestacions. La documentació no sempre cita el terme precaria, però li són equivalents les expressions «qui tenet» o bé «ubi habitat» ${ }^{39}$, Les contraprestacions que se solen anomenar són la tasca (generalment una onzena part de la collita), sola o acompanyada del servitium o parata o bé oblias: un pa (fogacia), capons, un quarter de cansalada... Tot i que la precària cessava a voluntat del propietari, sovint es mantenia indefinidament $i$ era renovada als fills, de forma que va ser un precedent clar de l'establiment. En algun cas, però, es fa constar la duració de la «precaria», limitada a una o dues generacions; així passa en una donació del bisbe Aeci al Penedès i, posteriorment, en una cessió al territori de Barcelona, a la partida de Banyuls, tot $\mathrm{i}$ que en tots dos casos el precarista havia de construir una casa $^{40}$. En el primer d'aquests casos, els pagaments anyals no semblen massa pesats, si, com sembla, es tractava d'una extensió una mica gran: es limiten a la parata («porcum unum, fochacias XIII, sexarios II de vino et sextarios II de cibaria»); cal tenir, però, en compte que els precaristes havien pagat una entrada («numos $\mathrm{V}$ aureos et modios III inter frumentum et ordeum») i havien de construir una casa. En canvi sobten la sèrie d'exigències de tipus personal: els precaristes quedaven sota el domini (tuitione) de la seu, la cessió es feia per dues vides (els obtentors i un fill seu), no

\footnotetext{
${ }^{38}$ «non porchos, non bervices, non agnos nec pernas nec ullum alium censum [...] sine ullo iugo servitutis" (Montmell); "non agnum, non arietem, non porcum, nec capones, non paravereda nec ulla importabilia honera [...] sola opera ad ipsum castrum facienda» (Ribes).

${ }^{39}$ «reservo ad ipsos pregararios illorum voces» Joaaquim MIRET, Los noms, doc. 40, p. 397; «ipsum mansum ubi habitat Sclutia», UdINA ABELló, La successió, ap. 1, doc. 77, p. 230-234, de 30 d'agost de 1009. De fet, quan «qui tenet» o bé «ubi habitat» va acompanyat de la menció "cum suos eres», es pot dubtar si ens trobem davant d'un precarista o d'un serf fiscal afocat: «vinditores sumus tibi Sancius [...] de alaude nostrum proprium [...] in primis ipso manso de Torondello ubi habitat Adam cum suos eres; et ipso manso de Beceda ubi habitat Formigo cum suos eres; [...] sic vendimus tibi iamdicto Sancio ipso alaudio", ACA, Cancelleria, perg. de Ramon Borrell, carp. 5 núm. 3, de l'any 998, FeliU-SALRACH, doc. 4.

${ }^{40}$ FÀBREGA, Diplomatari, doc. 319 , pp. 552-553 de 4 de desembre del 977; ACB, perg., 1 2-1306, de 14 d'abril del 1074.
} 
podrien abandonar la terra («si vos dimiseritis eadem terram [...] componatis [...] in duplo»), i fins i tot si el marit moria, la dona no es podia tornar a casar sense permís de la seu a risc de perdre la precària.

Sota el mateix nom de precària s'acostuma a considerar un contracte molt diferent, la "precaria oblata» dels juristes ${ }^{41}$. Es tracta de les anomenades donacions «reservato usufructu», els beneficiaris de les quals són sempre institucions eclesiàstiques. En aquestes donacions, teòricament voluntàries i pietoses, el donador es reserva la possessió del bé durant la seva vida o la seva descendència, a canvi del pagament de la tasca o, més rarament, d'altres parts de la collita o d'algun pagament en espècies (cera, capons...) o diners, i de l'acceptació de la senyoria dominical del beneficiari sobre les seves terres: de propietari es converteix així en precarista. Tot fa pensar que molt sovint aquestes donacions eren en realitat una forma de liquidació de deutes o d'obtenció de capital (en diner o en espècie) o bé de recerca de protección ${ }^{42}$.

El tipus de precària més favorable per al pagès conreador de terres alienes és l'anomenada complantació, contracte específic per a la plantació de vinya ${ }^{43}$, que permetia al complantador accedir a la propietat de part de

\footnotetext{
${ }^{41}$ Vegeu per exemple Luis García De Valdeavellano, Curso de Historia de las Instituciones españolas. De los orígenes al fiñal de la Edad Media, Madrid: ed. Revista de Occidente, 1968, p. 249.

${ }^{42}$ Com assenyala BonNASSIE, La Catalogne, I, p. 208, és difícil atribuir a un sobrepuix de pietat el fet que la major part de les donacions d'aquesta mena obtingudes per Sant Cugat en temps de l'abat Odó es concentressin a Sant Boi i a Sant Feliu de Llobregat; això mateix es pot dir del nombre elevat de donacions d'aquesta mena rebudes per l'església de Sant Miquel de Barcelona la dècada de 960 a 970 (Gaspar FELIU MONTFORT, Els inicis del domini territorial de la Seu de Barcelona, «Cuadernos de Historia Económica de Cataluña», XIV (1976), p. 4551). Indici de la no voluntarietat de moltes d'aquestes donacions és la donació "reservato usufructu" on l'església de Sant Miquel es anomenada a les afrontacions com a compradora, FÀBREGA, Diplomatari, doc. 75 , pp. 270-271. La recerca de protecció apareix clarament en la donació que els habitants de Sentmenat feren a la seu de Barcelona d'un bosc i les garrigues corresponents que ells mateixos havien comprat a un tal Bofill, «ut sub illarum cauta custodia ea omnia perfruamus", ACB, Libri Antiquitatum III,, doc. 291, f. 111. Molt possiblement els habitants de Sentmenat havien arribat a un arranjament amb Bofill, que devia reclamar drets sobre el bosc, on consta que s'hi estaven fent aprisions («silvam nostram cum cum suarum garricarum confinia, cum earum ruptum et inrumptum, terras cultas et heremas»); però tot l'acta de venda no es devien refiar que Bofill no insistís en les seves exigències i per això decidiren buscar el patrocini de la seu.

${ }^{43}$ Segons Rafael GIBERT, La "complantatio" en el Derecho Medieval Español, "Anuario de Historia del Derecho Español», XXIII (1953) p. 744, el considerar la «complantatio» com una precària era una especificitat dels territoris catalans. En efecte, sovint es troben expressions com "plantario quod nobis precaria fecisti", "ad complantandum vineas per precaria ad partes laborandum», "Causa precaria ad complantandum», UdINA, El Archivo Condal, doc. 152, de 29 d'abril del 961; ACB, perg. 1-2-728 de 8 de febrer del 1001, ACB, Libri Antiquitatum, I, núm
} 
la terra. La complantació ha estat considerada habitualment com una forma d'accès a la propietat per part de pagesos sense terra, però amb voluntat de treball: Bonnassie basà en aquesta idea l'origen de la fortuna de la família de Vives de Provençals ${ }^{44}$. De fet la creació d'una vinya requereix esforços i capitals que no sempre devien estar disponibles en mans d'un petit propietari; en tot cas figurar com a plantador en un contracte vol dir només que hom es feia càrrec de la plantada per a realitzar-la amb el propi esforç o amb l'esforç dels seus subordinats o llogats; d'altra forma no s'entendria com podien haver estat plantadors personatges com el jutge Oruç (1014), el bisbe Guillem de Torroja (1157) o bé el canonge Berenguer de Subirats $(1169)^{45}$.

Tot $\mathrm{i}$ que en alguns casos les seves càrregues no semblen superiors a les dels precaristes, no hi ha dubte de què, en conjunt, els serfs fiscals es trobaven en una situació de major subjecció; queda el dubte de si els podem posar en el mateix s̀ac amb els «homines sui» o els «manentes». Si fos així, tindríem una categoria de pagesos conreadors, adscrits a la terra, però sense cap dret sobre d'ella, que surt molt poc als documents, però que era segurament prou nombrosa. De vegades no sembla que haguessin de soportar càrregues superiors a les dels precaristes ${ }^{46}$, però els trobem també sotmesos a fortes prestacions: l'any 982 el comte Ramon Borrell donava al monestir de Sant Pere de Grau d'Escales el seu alou de la Corriu i enumerava les obligacions dels «homines» de l'alou ${ }^{47}$ : conrear el «dominicum», ajudar a la construcció del cenobi, baixar fusta del bosc i pagar «oblias» dues vegades a l'any. De fet hem de pensar que si no hi havia hagut cap tipus d'enfranqui-

260, de 20 de desembre del 1094.

${ }^{44}$ Pierre BONNASSIE, Une famille de la campagne barcelonaise et ses activités économiques aux alentours de l'An Mil, "Annales du Midi», LXXVI (1964).

${ }^{45} \mathrm{ACB}$, perg., 1-2-1112, Íd. Libri Antiquitatum, I, núm 113 i 115 respectivament.

${ }^{46}$ «unum mansum censualem quem tenet Seniofredus [...] cum omne censum et functione atque servitio que de prefato manso exire debet», ACA, Cancelleria, perg. de Berenguer Ramon I, carp. 5, núm. 45 , de 28 de setembre del 1023, Feliu-SALRACH, L'arxiu. núm. 46.

${ }^{47}$ «Ego domnus Borrellus comes et marchio donator [...] ad Scalas cenovii, ipsa Currize [...] debent ipsi homines servitium facere ipsum alodem [...] adoperare ad vineas plantare et ad hedificare aut ad harare cum alios covarios de sancto Petro. Et ipsas mansiones de sanctum Petrum qui ibidem sunt aut condirigere aut ulla opera facere. Et de insuper de ipsos montes quod superius sunt tabulas trahere vel scandas facere vel ad sanctum Petrum portare faciant in Scalas cenovii. Et insuper alium servitium oblias donare faciant de Natale Domini perna I, sestari de civada et fochacas II et sestari de vino. Ad ipsas vindemias donare faciant perna I aut porcello", Cebrià BARAUT, Els documents dels segles IX $i X$, conservats a l'Arxiu Capitular de la Seu d'Urgell, "Urgellia», 2 (1979), doc. 192, p. 27-28, de 19 de gener del 982. 
ment, requeien sobre ells les prestacions que vèiem condonar als habitants de Montmell o de Sant Pere de Ribes.

El darrer esglaó social (ja ni esglaó, donat que no eren considerats part de la societat) eren els esclaus que, tot i en regressió, foren sempre presents, com Bonnassie ha demostrat prou bé ${ }^{48}$. Convé potser només indicar que cap a l'any mil en podem distingir tres categories: els esclaus hereditaris, descendents de l'esclavatge antic, les sotmesos a esclavitud per decisions judicials ${ }^{49}$ i els captius musulmans. Encara que els esclaus fossin escassos, la població savia prou bé que significava «servili modo subicere», com expressaven els esposos Sindila i Maria en lliurar-se al bisbe de Barcelona.

\section{CANVIS DEGUTS A LA IMPLANTACIÓ DEL FEUDALISME}

Fins a quin punt la pagesia es veié afectada per la implantació de les senyories feudals? Aquesta implantació, comportà canvis profunds en les etructures de propietat o consistí bàsicament en la transformació dels vicaris anteriors en senyors feudals i en l'apropiació per aquests de la part dels impostos i les rendes que anteriorment els vicaris feien a mans al comte? Les respostes passen en primer lloc per examinar l'evolució de l'alou pagès, o sigui de la pagesia propietària lliure. Per Bonnassie, i gairebé per a tothom

\footnotetext{
${ }^{48}$ Bonnassie, La Catalogne, I, p. 298-302. Per una visió general del problema vegeu Id., Survie et extinction du régime esclavagiste dans l'Occident du haut Moyen Âge (IV'-IX' $s$.$) ,$ "Cahiers de Civilisation Médiévale», XXVIII, 4 (1985), republicat a "L’Avenç", 131 (1989), amb el títol Supervivència i extinció del règim esclavista a l'alta edat mitjana. Segles IV-XI, i també en el recull de treballs del mateix BONNASSIE, Del esclavismo al feudalismo en Europa occidental, Barcelona, 1993.

${ }^{49} \mathrm{Com}$ a exemple de lliurament judicial ja he citat el cas de Sindila i Maria, que es lliuraren al bisbe amb els seus béns per haver mort la seva filla. També devia respondre a un lliurament judicial la servitud expressada en un document de l'any 829 en què Eutímia donava al seu nebot Guisad «una binea qui fuit de serbos meos Felice et Moderata» BARAUT, Els documents (2) doc. 3 , p. 28-29, la donació de «ipso manso de Orreto de ipsos nostros famulos, quod sunt Tudericum et Provizio» MARCA, Marca Hispanica, ap. LXI, col. 836-837, de l'any 901, i la venda feta pel jutge Miró al bisbe Guisad d'Urgell: «vindo tibi servos meos nomine Atila et Rechosindo cum prolibus eorum et eorum alode» BARAUT, Ibidem, doc. 2, p. 17-19. Fins i tot un document de 843 permet pensar en l'existència d'esclaus públics: «in pago Confluente, villa que vocatur Prata cum mancipiis que ad idem Confluentem pertinent», MARCA, Ibidem, ap. XV, col. 778.
} 
fins $\operatorname{ara}^{50}$, la desaparició de l'alou s'hauria produït al llarg del s. XI com a conseqüència de la irresistible pressió senyorial a través de vendes, donacions més o menys voluntàries a institucions eclesiàstiques, confiscacions judicials o sotsmissions arbitràries.

Podem plantejar però, com a hipòtesi alternativa, si l'alou pagès havia estat mai una situació generalitzada i, pel que fa a la desaparició de l'alou rendista, dominical, si no fou deguda en gran part a la difusió dels establiments, a la concentració de la propietat alodial (herències, compres, donacions a institucions eclesiàstiques) i a l'entrada dels alous en el joc de dependències senyorials.

En tot cas els canvis en la propietat alodial no eren el problema de la majoria dels pagesos conreadors; la situació d'aquests sembla haver evolucionat d'una banda cap a la propietat, ni que fos reduïda al domini útil obtingut mitjançant la precària, de l'altra cap a una major subjecció com a conseqüència de la violència senyorial. La condició pagesa al s. XII era sens dubte diferent de la dels segles anteriors, però no tant com indicava la tesi tradicional.

L'impacte de l'aparició del feudalisme sobre la condició pagesa està lligat a la qüestió de fins a quin punt les imposicions feudals eren noves; com a hipòtesi de treball com a mínim, crec que cal considerar la possibilitat de què una documentació més explícita faci conèixer prestacions que anteriorment no eren mencionades o bé ho eren de forma molt global. Per exemple, les càrregues esmentades en el document de Sanaüja, amb la descripció de les quals Bonnassie inicia l'estudi de la implantació de la senyoria banal, eren realment noves? Les imposicions que hi figuren són un dret sobre el vi (la compra), l'host, uns lliuraments d'aliments que poden ben correspondre a la parata que figura en documents del s. X, un cens relativament mòdic (un sester de civada i una garba), serveis d'obra i de tragí: tot això cap dins del servitium i les oblias dels documents antics. ${ }^{51} \mathrm{La}$

\footnotetext{
${ }^{50}$ Vegeu per exemple Manuel RIU, La feudalització del camp català, «Cuadernos de Historia Económica de Cataluña», XIX (1978), republicat a «II Curs d'Història de Catalunya (novembredesembre de 1977). Estructura social i econòmica del camp català». Barcelona, Ajuntament de Barcelona, Institut Municipal d'Història, 1978, i també a: Miquel TARADELl et al. Estructura social i econòmica del camp català, Barcelona, Ed. de la Magrana-Institut Municipal d'Història, 1983.

${ }^{51}$ El servei d'obra apareix el 954 amb l'obligació dels aprisionadors atrets per Guitard al seu alou de Freixa, obligats a construir una torre entre tots, FonT RIUS, Cartas, doc. 5, p. 9-10; si aquest exemple sembla poc adequat, es pot recordar que també és citat a la carta de franqueses del comte Borrell per a Cardona (986): «faciatis ipsa opera ab ipso castro», Ibidem,
} 
part més nova i la millor mostra de l'arbitrarietat senyorial és segurament la legislació sobre la caça, però no recordo cap altre document amb clàusules semblants. Eren noves per exemple les forcias et toltas que junt a les albergas es citen en un document de temps del comte Ramon Berenguer I $?^{52}$ o eren les obligacions normals dels masos servils?

Evidentment a l'hora de parlar d'imposicions no es tracta d'esbrinar si la pressió senyorial era dura, punt que no crec que susciti desacords, sinó més aviat si la situació anterior sota el poder dels representants del comte, sovint els mateixos personatges transformats de vicaris a senyors, era gaire millor: la presumpció que els comtes o els seus vicaris es comportaven envers els seus súbdits amb més mirament que la resta dels senyors forma part de l'aparell de propaganda habitual de les monarquies, però no té res a veure amb la realitat i per tant amb la ciència històrica.

Vegem com descriu la situació Freedman:

Amb el declivi de l'autoritat pública els pagesos perderen la seguretat de les tinences i començaren a estar sotmesos a diverses exaccions. Algunes de les noves exaccions eren, de fet, impostos públics que havien estat usurpats; d'altres eren producte de la inventiva privada. Les obligacions militars que abans devien als comtes foren transformades al servei dels castells privats amb els corresponents districtes, que es covertiren en unitats efectives de jurisdicció senyorial (castra). Els drets militars vinculats al castell inclö̈en l'alberga i el receptum (la manutenció dels cavallers i els cavalls i la provisió de farratge i aliments per al castell) prestacions de treball per a mantenir el castell (batuda) i vigilància $i$ guiatge dels exèrcits (guaita).

També hi hagué exaccions completament arbitràries que constituïren el que Bonnassie anomena la «pirateria senyorial». Generalment conegudes com a toltas o forcias, aquestes exaccions no eren simplement drets públics usurpats, (tot i que la questia, l'antic ajut al comte, hi estigué sovint vinculada), sinó que eren manifestacions de noves formes de poder opresor $^{53}$.

doc. 9 , p. 14-18, i, pràcticament amb les mateixes paraules, a la carta de població de Ribes (990), tants cops citada. El tragí apareix també clarament a la donació de La Corriu a Sant Pere de Grau d'Escales, del 982, BARAUT, Els documents (2), doc. 192, p. 27-28.

${ }^{52}$ «pignora que misit Gilabertus [...] de ipsos mansos [...] ubi habitat Guillermus Hosten [...] quantum nos abere debemus de ipsos mansos, ipsas albergas et forcias et toltas, sic impignoramus tibi [...] ipsos mansos», ACA, Cancelleria, perg. de Berenguer Ramon I, núm. 118, sense data, Feliu-SAlRACH, L'arxiu, doc. 792.

${ }^{53}$ FreEdMan, Els orígens, p. 90. 
La cita és una mica llarga, però val la pena: per començar, no sé d'on treu que els pagesos perderen la seguretat de les tinences; pel que fa a les exaccions, deixant de banda l'error de la batuda, la resta d'obligacions són totes anteriors i al pagès tant li feia si el beneficiari era el comte o el senyor. La única possible novetat són les toltas o forcias; també les prestacions en treball es troben clarament a la donació de La Corriu: igualment que les toltas i forcias, les prestacions en treball podien molt ben ser antigues prestacions servils. Fins i tot els lliuraments arbitraris estan testificats de molt antic: la carta de franqueses concedida pel comte Ramon de Tolosa a Gerri el 859 eximeix el monestir, entre altres coses, de «inlicitas hoccasiones ${ }^{54}$ i la carta de franqueses de Sant Pere de Ribes parla de «importabilia honera».

Una cosa semblant podem dir d'una altra afirmació de Freedman: «La implicació d'un vincle involuntari (home) que lligués un pagès a un senyor aparegué per primera vegada a finals del segle $\mathrm{XI}{ }^{55}$; però, eren diferents aquest «homes» dels que apareixen en els diplomes carolingis? hi cap ben bé un dubte raonable.

De tota manera és evident que la pressió senyorial anà degradant la situació de la pagesia ${ }^{56}$, però ens podem preguntar si aquesta degradació fou deguda només (o bàsicament) a l'increment de la pressió senyorial que comportà la instauració del feudalisme, o bé també a la generalització de la situació dels més desafortunats a tots aquells que, havent d'anar a suplicar la concessió d'una terra, es trobaven davant d'exigències creixents. No és

\footnotetext{
${ }^{54}$ «iubemus [...] ut nullus ex vobis [...] supra nominato vir venerabili Diligato abbate neque super alode vel beneficium Sancti Petri vel ad suos monachos neque super illorum homines tam ingenuos quam servos [...] non mansionaticos, non parveredos tollendos, non vactas, non hoste neque cenobrio, non fideiussores tollendos neque placita requirenda, nullas redibitiones nec inlicitas hoccasiones non ad eos requiratis", Ramon d'ABADAL I DE VINYALS, Els comtats de Pallars $i$ Ribagorça, vol. III de Id. Catalunya carolíngia. Barcelona, Institut d'Estudis Catalans, 1955 , doc. 55, p. 393-394.

${ }^{55}$ FrEEDMAN, Els orígens, p. 96; pàgines abans (p. 92) Freedman precisa la data de 1063, corresponent a un document d'El Talladell (Tàrrega) publicat per Agustí ALTISENT, Diplomatari de Santa Maria de Poblet, vol. I. Anys 960-1177. Barcelona, Abadia de Poblet-Generalitat de Catalunya, Departament de Cultura, 1993, doc. 19, p. 36-37.

${ }^{56} \mathrm{~L}$ 'exemple més espectacular que en conec és una llista de finals del s. XII, que devia voler ser exhaustiva, i que enumera entre els drets del senyor, i per tant les obligacions del pagès, els censos, les exaccions, el llòsol, les franqueses, les joves $i$ tragins, les obres, guaites, host i cavalcada, les redempcions d'homes $\mathrm{i}$ dones, els drets de justícia, la firma d'esponsalici, exòrquies, cugúcies, intèsties perjuris, Jesús AlTURO I PERUCHO, L'arxiu antic de Santa Anna de Barcelona del 942 al 1200 (aproximació històrico-lingüística), 3 vols., Barcelona, Fundació Noguera, 1985, núm. 528.
} 
fàcil de respondre, però ens inclinaríem més aviat a creure que ens trobem davant d'un doble procés: d'una banda, pèrdua de la propietat i sotsmissió a senyoria dominical dels petits aloers conreadors; de l'altra, afloració documental de la massa de «manents» o de «tenents» que, com hem indicat més amunt, devien formar fins al s. X la majoria dels conreadors i que ara queden bàsicament assimilats als antics aloers reduïts a parcers, com a pagesos de mas o de sagrera, amb una situació econòmica i social que per alguns d'ells era pitjor que la dels seus pares, però per altres podia representar una petita millora.

La qüestió clau en tot aquest tema és si la situació de la pagesia havia millorat o s'havia degradat del s. X al s. XII. La historiografia vigent aposta sense embuts per l'empitjorament: la millora econòmica hauria suscitat la cupiditat dels poderosos, amparada en la coacció i la violència, $\mathrm{i}$ hauria provocat una major subjecció dels humils. Bonnassie i Ruiz Doménech, de forma paral.lela, però independent, arriben pràcticament a les mateixes conclusions, acceptades també per Freedman, i que Salrach recull i resum en un títol magníficament lacònic i definitori: «Esclavitud, llibertat, servitud $»^{57}$.

Un títol magnífic, però desgraciadament poc ajustat a la realitat: no tothom era esclau, pocs van assaborir la plena llibertat, la nova dominació, que no per tots era servitud, anava acompanyada de drets de propietat.

\section{RÉSUMÉ}

D'après une longue tradition historiographique la possibilité d'accéder à la propriété de la terre par apprision entraîna dans la Marque Hispanique un essort de la paysannerie alleutière, qui définit une période d'aisance relative entre l'esclavage ancien et la féodalité. Cet article nous présente une thèse fort éloignée de ces postulats: jusqu'au milieu du XIe siècle la paysannerie catalane était pour la plupart, soit esclave soit soumise à des degrés très variables de dépendance; dans ce contexte, la mutation féodale ne put en aucune façon entraîner une forte dégradation de la condition des paysans.

\footnotetext{
${ }^{57}$ Bonnassie, La Catalogne, II, p. 575-585; José E. RuIz DoMÈnECH, Nota acerca de la evolución de los grupos sociales dependientes en Cataluña y el sur de Francia durante los siglos IX y X (c. 879-963), «Studia Storica. Historia Medieval», I, 2 (1983); FREEDMAN, Els orígens; SALRACH, Esclavitud.
} 


\section{SUMMARY}

The possibility of get land through the aprisio during the Reconquest has helped to spread the idea that aprisio made it possible the birth of a stratum of free peasant ownwer (alodial) and it allowed for a time of relative well-being between the ancient slavery and the feudal submission. This article argues that most of the pre-feudal peasantry was slave or subject to various degrees of serfdom and that the imposition of feudalism could not make worse the previous status. 